\title{
Fatigue life and self-induced volumetric changes of CARDIFRC
}

\author{
D. Nicolaides*, A. Kanellopoulos $\dagger$ and B. L. Karihaloo
}

Frederick University; University of Cyprus; Cardiff University

A class of ultra-high-performance fibre-reinforced cementitious composites (UHPFRCC) has been developed at Cardiff university and registered under the trade name CARDIFRC. The method of its production and its mechanical and fracture properties were reported previously in a series of papers in Magazine of Concrete Research. Here the results of recent fatigue and shrinkage tests on this material are reported. As with the mechanical and fracture properties, it is shown that an even and uniform distribution of fibres throughout the bulk of the material is crucial to its superior fatigue performance and to the reduction in the shrinkage strains.

\section{Introduction}

In recent years there has been a growing interest in the fatigue behaviour of concrete subjected to repeated loading. The fatigue strength of concrete is defined as the fraction of the static strength that it can support repeatedly for a given number of cycles. Fatigue failure occurs when a concrete structure fails catastrophically at less than the design load after being exposed to a large number of load reversals. Concrete fatigue is a result of damage accumulation from the progressive growth of small imperfections existing in the material by repetitive loads. These imperfections may be caused by shrinkage or the application of external loads. The latter leads to progressive bond deterioration between coarse aggregates and the cement paste or to the development of cracks existing in the cement paste.

The addition of fibres to concrete has a twin effect on its fatigue performance. By bridging the microcracks, the fibres can retard the crack growth process, thus increasing its fatigue life. But if they are not properly bonded to the surrounding mix, they can form the nuclei of additional defects and thus reduce the fatigue life of concrete. In the ultra-high-performance fibre-reinforced

* School of Engineering, Frederick University, 7-9 Filokyprou Street, Palouriotissa, 1036, Nicosia, Cyprus

$\dagger$ University of Cyprus, 75 Kallipoleos Avenue, P.O. Box 20537, 1678, Nicosia, Cyprus

$\ddagger$ School of Engineering, Cardiff University, Cardiff, CF24 3AA, UK

(MACR 900149). Paper received 12 August 2009; last revised 17 December 2009; accepted 23 December 2009. Published online ahead of print 23 June 2010 cementitious composite (UHPFRCC) under investigation, the bond between the fibres and surrounding mix has been strengthened and densified by the use of silica fume and superplasticiser and it is the aim of this study to reveal how this has influenced its fatigue life.

A characteristic feature of the UHPFRCC under investigation is its very low porosity and the discontinuous capillary pore structure of the cement paste. Moreover, because of a low water-to-binder ratio, changes in temperature and moisture content (i.e. relative humidity) can induce volume changes during hardening far in excess of those observed in conventional concretes. These self-induced volume changes are best measured volumetrically commencing from the moment of casting. However, such measurements are difficult to make in practice, and so instead linear measurements are made on specimens after the initial setting period. This has led to considerable disagreement in the scientific community on merits of each method (Jensen and Hansen, 1995, 2001). It is not the intention here to argue in favour of one or the other method. The present researchers' aim is limited to revealing the role of fibres in the reduction of the considerable self-induced volume changes. For this the simpler linear measurement technique is used and the self-induced volume changes are compared for specimens with and without fibres.

\section{CARDIFRC}

CARDIFRC is a new class of UHPFRCC characterised by high compressive strength (in excess of 
$200 \mathrm{MPa}$ ), splitting/flexural strength (up to $30 \mathrm{MPa}$ ) and high energy absorption capacity (in excess of $17000 \mathrm{~J} / \mathrm{m}^{2}$ ). This has been made possible by the use of large amounts (up to $8 \%$ by volume) of brass-coated short steel fibres of two lengths (6 and $13 \mathrm{~mm}$ long, $0.16 \mathrm{~mm}$ diameter) in a cementitious matrix densified by the use of silica fume. The matrix contains only very fine graded quartz sand, instead of ordinary river sand and coarse aggregates. By optimising the grading of fine quartz sands, the water demand was considerably reduced without affecting the workability of the mix. This was achieved using novel mixing procedures described by Karihaloo et al. (2005). Computer tomography imaging and sectioning of specimens have confirmed that these procedures ensure a remarkably homogeneous mix with a uniform distribution of fibres in thin sections ( $<50 \mathrm{~mm}$ thick) (Benson et al., 2005). The mix proportions of a mix of the CARDIFRC class and its typical properties are given in Tables 1 and 2 (Karihaloo et al., 2005).

\section{Experimental set-up}

\section{Fatigue experimental set-up}

The fatigue tests were carried out in three-point bending in a stiff self-straining testing frame, fitted with a $2500 \mathrm{kN}$ dynamic-static actuator. The beams $(35 \times 90 \times 360 \mathrm{~mm})$ were simply supported over a span of $280 \mathrm{~mm}$. The choice of a thin beam $(35 \mathrm{~mm}$ deep) was dictated by the fact that CARDIFRC is mainly intended for use in the form of thin strips in

Table 1. Mix proportions for optimised CARDIFRC I (per $\left.\mathrm{m}^{3}\right)$

\begin{tabular}{l|c}
\hline Constituents: kg & Mix I \\
\hline Cement & 855 \\
Microsilica & 214 \\
Quartz sand: & 470 \\
$9-300 \mu \mathrm{m}$ & 470 \\
$250-600 \mu \mathrm{m}$ & - \\
$212-1000 \mu \mathrm{m}$ & - \\
$1-2 \mathrm{~mm}$ & 188 \\
Water & 28 \\
Superplasticiser & 390 \\
Fibres, 6 mm & 78 \\
Fibres, 13 mm & $0 \cdot 22$ \\
Water/cement ratio & $0 \cdot 18$ \\
Water/binder ratio &
\end{tabular}

Table 2. Typical material properties of CARDIFRC I

\begin{tabular}{l|r}
\hline Material properties & Mix I \\
\hline Indirect tensile strength: MPa & 27 \\
Fracture energy: J/m & 17000 \\
Compressive strength: $\mathrm{MPa}$ & 200 \\
Modulus of elasticity: $\mathrm{GPa}$ & 48 \\
\hline
\end{tabular}

small-volume applications (e.g. retrofitting of damaged concrete structures) owing to the high cost of fibres (Alaee and Karihaloo, 2003; Alaee et al., 2002; Karihaloo et al., 2002). Moreover, the novel mixing procedures (Benson and Karihaloo, 2005a; Karihaloo et al., 2005) ensure an even and uniform distribution of the fibres within the mix in such thin strips. In view of the high cost of fibres, a commercial variant of the material has been developed in collaboration with a leading concrete construction company. It differs from the original CARDIFRC mixes through

(a) a reduction in the cost by replacing expensive brass-coated small steel fibres with less expensive longer steel fibres

(b) the avoidance of the need for vibratory compaction by creating a self-compacting mix

(c) the creation of a sustainable and environmentally friendly material with a low carbon footprint.

This commercial mix is currently undergoing a thorough performance evaluation. A recent cost analysis by the industrial partner who can procure the ingredients at much lower wholesale prices has shown that this commercial variant is highly competitive even in very large-volume applications for which steel is preferred at present.

Four short cylindrical clamps were arranged on the supports to prevent the beam from moving, during the cyclic load application. These clamps did not actually come in contact with the specimen, unless it started to move from its original position. None of the specimens were observed to move during fatigue testing. The load amplitude, the frequency, the applied number of cycles and the magnitude of central displacement at failure were digitally controlled. Four types of measurement were recorded for each test beam

(a) the load from the load cell of the testing machine

(b) the vertical deflection at the mid-span

(c) the time parameter

(d) the number of cycles to failure.

The vertical deflection was measured by a single linear variable differential transducer (LVDT) placed underneath the testing beam, at the mid-span. The specific LVDT was calibrated for a very narrow range of deformation $( \pm 2.5 \mathrm{~mm})$, because the deformation of the beam during its fatigue life was expected to be very small. A mechanical stop was installed $10 \mathrm{~mm}$ below the beam at its mid-span in order to prevent damage to the LVDT should the beam fail suddenly.

The cyclic tests were carried out in the load ranges between $10 \%$ and $90 \%, 10 \%$ and $85 \%$, and $10 \%$ and $80 \%$ of the monotonic flexural strength. Fatigue specimens were not all cast from the same batch, in order to explore the possible effect of batching on the consistency of the experimental results. The monotonic flexural strength was also measured in three-point bending on specimens of the same dimensions, and the mean

Magazine of Concrete Research, 2010, 62, No. 9 
value from at least five specimens was $46 \cdot 4 \mathrm{MPa}$. The fatigue tests were performed in load control. Each specimen was first subjected to three slow cycles up to $50 \%$ of the monotonic flexural strength of the material to remove any slack in the test set-up before any recordings were made. This stress level was chosen because it lies well within the elastic range of the material. It should be noted that, unlike most previous studies on the fatigue of fibre-reinforced concrete (FRC), the specimens tested in this study were not precracked before cyclic loading (Cachim et al., 2002).

The specimens were subjected to a sinusoidal cyclic fatigue loading with a frequency of $6 \mathrm{~Hz}$. The choice of frequency of the sinusoidal load was dictated solely by the time it would take for the test beam to reach a minimum of $10^{6}$ cycles. The test was stopped after the specimen failure or after one million load cycles, whichever occurred first. A few specimens were tested up to $20 \times 10^{6}$ cycles (Farhat et al., 2007).

\section{Self-induced shrinkage experimental set-up}

For the self-induced shrinkage experiments prismatic specimens (with or without fibres - SF and SNF respectively) with dimensions $50 \times 50 \times 250 \mathrm{~mm}$ were used. It is known from the literature that for cementbased materials containing large quantities of cement and mineral-chemical admixtures (cement replacement materials and water-reducing agents), the setting of the mix is considerably delayed (Brooks et al., 2000; Morin et al., 2001). Moreover, in many cases reported in the literature where linear measurements of self-induced shrinkage deformations were performed, a minimum setting time of $12 \mathrm{~h}$ was selected (Jiang et al., 2005; Yang et al., 2005). Similar observations have been reported for high-performance cement-based composites with water-to-cement (w/c) ratio as low as $0 \cdot 17$. Cheyrezy and Behloul (2001) have selected $19 \mathrm{~h}$ as the setting time of reactive powder concrete, a cementbased composite very similar in composition to CARDIFRC. In the light of these findings the specimens remained in the steel moulds for about $17 \mathrm{~h}$ in order for them to harden sufficiently well for handling, after which the specimens were demoulded and acoustic vibrating wire gauges were bonded to the ends.

After bonding the gauges, the beams were carefully wrapped, taking care not to cause any damage to the gauges. The specimens were wrapped with vinyl acetate sheets and aluminium adhesive tape, ensuring the adiabatic conditions needed for the test, as well as minimising any moisture exchange with the surrounding environment. After wrapping the specimens and insulating them properly, they were connected to a data acquisition system. For the first seven days, readings were recorded every $15 \mathrm{~min}$. The interval between the readings was increased progressively after this initial period. The choice of small time step between the readings in the first seven days was dictated by the knowledge that the bulk of the self-induced shrinkage strains occur in this period. This has been confirmed by the measurements, as will be clear in the following sections. After day 20 the development of shrinkage strains seems to have stabilised sufficiently for the interval between the readings to be substantially increased.

\section{Experimental results and discussion}

\section{Fatigue}

The fatigue life of specimens (i.e. the number of cycles to failure, $N$ ) is shown in Table 3 . It is clear that the test results are highly consistent for the load ranges between $10 \%$ and $85 \%$ and between $10 \%$ and $80 \%$; all eight specimens sustained in excess of $10^{6}$ cycles without failure. Moreover, none of these eight specimens had developed any visible cracks on the surface. On the other hand, in the load range 10-90\% some specimens failed below $10^{6}$ cycles and some did not. It can therefore be safely assumed that the fatigue limit of CARDIFRC is approximately at $85 \%$ of its monotonic flexural strength. Below this limit none of the tested specimens failed, not even after a few of them had been subjected to $20 \times 10^{6}$ cycles (Table 3 ). That the observed fatigue limit is very high, not often associated with cement-based materials, is consistent with the response of CARDIFRC in direct tension (Benson and Karihaloo, 2005b), which shows that its elastic range extends to about $85 \%$ of its ultimate tensile strength. However, in contrast to conventional FRC, this extended elastic range of CARDIFRC is followed by a very substantial strain hardening range.

In order to verify whether or not any internal cracks had developed in the specimens that had sustained at least $10^{6}$ cycles without failure, they were tested post-

Table 3. Flexural fatigue test experimental results (CARDIFRC $360 \times 90 \times 35 \mathrm{~mm})$

\begin{tabular}{l|c|c|c|c|c}
\hline \multirow{2}{*}{$\begin{array}{l}\text { Load amplitude } \\
\text { range: } \% P_{\mathrm{u}}\end{array}$} & \multicolumn{5}{|c}{ Fatigue life: $N$} \\
\cline { 2 - 6 } & $N_{1}$ & $N_{2}$ & $N_{3}$ & $N_{4}$ & Average fatigue life: $N$ \\
\hline $10-90$ & $10^{6}$ & 21564 & 9315 & $10^{6}$ & - \\
$10-85$ & $10^{6}$ & $10^{6}$ & $10^{6}$ & $20 \times 10^{6}$ & $10^{6 *}$ \\
$10-80$ & $10^{6}$ & $10^{6}$ & $10^{6}$ & $20 \times 10^{6}$ & $10^{6 *}$ \\
\hline
\end{tabular}

*The average fatigue life considers only the first $10^{6}$ cycles sustained by specimen No. 4 . 
fatigue in static three-point bending. The purpose of this static testing was to compare the post-fatigue flexural strength and the static load-deflection envelope with the pre-fatigue test results. As mentioned earlier, none of these specimens had any visible cracks on the external surfaces at the end of fatigue testing. The specimens tested at $80 \%, 85 \%$ and $90 \% P_{\mathrm{u}}$ in fatigue showed a small increase in their flexural strength (Table 4). This increase in flexural strength was believed to be dependent on the maximum flexural fatigue stress $\left(S_{\max }\right)$. This observation confirms previously noted results in the literature, that prior cycling may lead to an improvement in strength (Naaman and Hammoud, 1998; Naaman and Harajli, 1990; Parant et al., 2007; Ramakrishnan et al., 1996; Rossi and Parant, 2008). It was suggested that this increase in strength is due to densification of the material, caused by stress cycling. However, it is likely that there are other mechanisms also involved in the increase of the post-fatigue flexural strength in UHPFRCCs which remain to be explored.

\section{Self-induced shrinkage}

Twelve prisms having dimensions $50 \times 50 \times$ $250 \mathrm{~mm}$ have been made for each type of mix (with and without fibres). The effect of fibres on the reduction of self-induced shrinkage strains is pronounced, as can be clearly observed in Tables 5 and 6 . The inclusion of fibres results in $74 \%$ decrease in the selfinduced shrinkage strains. Although there are findings suggesting that both unhydrated cement grains and hydration products can act as a restraint on the selfinduced shrinkage in plain cement-based matrices (Bentz and Jensen, 2004; Farhat et al., 2007; Jensen and Hansen, 1996), it is the additional restraint provided by the large volume $(6 \%)$ of small fibres used in CARDIFRC that is responsible for the bulk of the reduction in the self-induced shrinkage strains. Figure 1 shows the variation of the self-induced shrinkage strain with time for mixes with and without fibres (up to 75 days).

Table 4. Experimental peak loads and tensile/flexural strengths of intact CARDIFRC beams $(360 \times 90 \times 35 \mathrm{~mm})$, tested in three-point bending, after they have been subjected to fatigue loading

\begin{tabular}{l|c|c|c|c|c|c}
\hline \multirow{2}{*}{ Beam number } & \multicolumn{2}{|c|}{$10-90 \% P_{\mathrm{u}}$} & \multicolumn{2}{c|}{$10-85 \% P_{\mathrm{u}}$} & \multicolumn{2}{c}{$10-80 \% P_{\mathrm{u}}$} \\
\cline { 2 - 7 } & $P_{\mathrm{u}}: \mathrm{kN}$ & $f_{\mathrm{t}}: \mathrm{MPa}$ & $P_{\mathrm{u}}: \mathrm{kN}$ & $f_{\mathrm{t}}: \mathrm{MPa}$ & $P_{\mathrm{u}}: \mathrm{kN}$ & $f_{\mathrm{t}}: \mathrm{MPa}$ \\
\hline 1 & $14 \cdot 65$ & $55 \cdot 81$ & $12 \cdot 65$ & $48 \cdot 19$ & $14 \cdot 30$ & $54 \cdot 48$ \\
2 & - & - & $14 \cdot 64$ & $55 \cdot 77$ & $13 \cdot 70$ & $52 \cdot 19$ \\
3 & - & - & $14 \cdot 30$ & $54 \cdot 48$ & $12 \cdot 40$ & $47 \cdot 24$ \\
4 & $12 \cdot 88$ & $49 \cdot 07$ & $13 \cdot 33$ & $50 \cdot 78$ & $13 \cdot 60$ & $51 \cdot 81$ \\
Avge strength & & $52 \cdot 44$ & & $52 \cdot 30$ & & $51 \cdot 43$ \\
\hline
\end{tabular}

Table 5. Average shrinkage strain ( $\mu \varepsilon$ ) values (with coefficient of variation (COV)) for mixes with (SF) and without fibres (SNF) at the end of each time interval

\begin{tabular}{|c|c|c|c|c|c|c|c|}
\hline & \multicolumn{7}{|c|}{ Time: days } \\
\hline & 1 & 2 & 3 & 4 & 5 & 6 & 7 \\
\hline Average shrinkage strain, SF: $\mu \varepsilon$ & $99 \cdot 42$ & $160 \cdot 17$ & $212 \cdot 09$ & $250 \cdot 11$ & $278 \cdot 94$ & $305 \cdot 03$ & $328 \cdot 34$ \\
\hline $\mathrm{COV}$ & $9 \cdot 29$ & $7 \cdot 66$ & $6 \cdot 81$ & $5 \cdot 86$ & $5 \cdot 59$ & $5 \cdot 04$ & $4 \cdot 91$ \\
\hline Average shrinkage strain, SNF: $\mu \varepsilon$ & $143 \cdot 82$ & $248 \cdot 52$ & $329 \cdot 91$ & $391 \cdot 19$ & $442 \cdot 31$ & $485 \cdot 23$ & $521 \cdot 63$ \\
\hline $\mathrm{COV}$ & $2 \cdot 37$ & $2 \cdot 09$ & $2 \cdot 04$ & $2 \cdot 07$ & 1.94 & 1.92 & $1 \cdot 89$ \\
\hline
\end{tabular}

Table 6. Average shrinkage strain ( $\mu \varepsilon)$ values (with COV) for mixes with (SF) and without (SNF) fibres at the end of each time interval

\begin{tabular}{|c|c|c|c|c|c|c|c|}
\hline & \multicolumn{7}{|c|}{ Time: days } \\
\hline & 10 & 20 & 30 & 40 & 50 & 60 & 75 \\
\hline Average shrinkage strain, SF: $\mu \varepsilon$ & $404 \cdot 78$ & $496 \cdot 89$ & $479 \cdot 53$ & $515 \cdot 69$ & $518 \cdot 57$ & $540 \cdot 73$ & $577 \cdot 00$ \\
\hline $\mathrm{COV}$ & $3 \cdot 98$ & $2 \cdot 87$ & $2 \cdot 61$ & $2 \cdot 20$ & $2 \cdot 21$ & 1.97 & $1 \cdot 66$ \\
\hline Average shrinkage strain, SNF: $\mu \varepsilon$ & $589 \cdot 16$ & $678 \cdot 22$ & $754 \cdot 25$ & $775 \cdot 53$ & $842 \cdot 41$ & $903 \cdot 01$ & $1000 \cdot 24$ \\
\hline COV & $1 \cdot 87$ & $2 \cdot 11$ & $2 \cdot 32$ & $1 \cdot 63$ & $1 \cdot 58$ & $1 \cdot 62$ & $1 \cdot 45$ \\
\hline
\end{tabular}




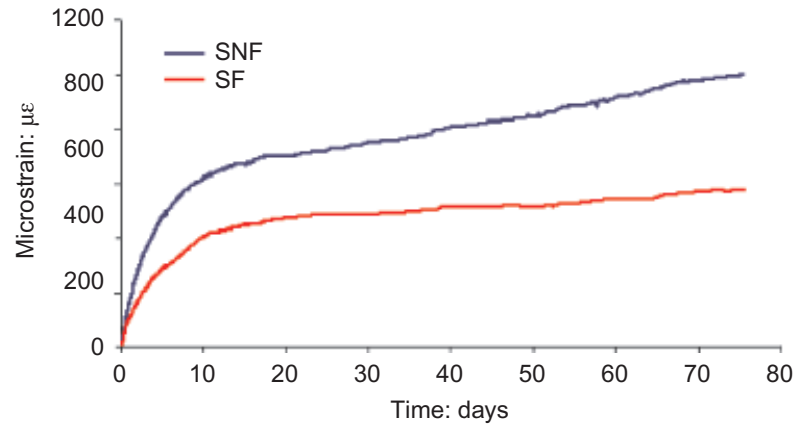

Figure 1. Shrinkage strain variation with time for mixes with (SF) and without (SNF) fibres (up to 75 days)

\section{Conclusions}

CARDIFRC exhibits excellent fatigue strength, up to $85 \%$ of its flexural strength, without any significant internal damage. This is consistent with its uniaxial tensile response (Benson et al., 2005), which is linear up to at least $85 \%$ of the tensile strength. This excellent fatigue behaviour can be attributed to the following factors: the absence of large aggregates (i.e. internal sites of stress concentrations); strong interfacial bond between the fibres and matrix; and the even and uniform distribution of fibres within the specimens, which prevent the growth and coalescence of any microcracks.

The shrinkage strains, which are primarily of autogenous and chemical nature, with perhaps a small contribution from drying despite the precautions taken to prevent loss of moisture to atmosphere, are, as expected, large for this kind of material because of the high content of cement and the low w/c ratio. The development of these strains is especially rapid up to the first 10 days, but the increase thereafter takes place at a substantially reduced rate. The presence of fibres is found to have a substantial beneficial effect in restraining the shrinkage of CARDIFRC matrix. In fact, the strains are reduced to levels expected of high-strength concretes. Moreover, the fibres prevent the formation of shrinkage cracks, as none were observed on the surfaces of the specimens even after 75 days.

\section{References}

Alaee FJ and Karihaloo BL (2003) Retrofitting RC beams with CARDIFRC. Composites for Construction 7(3): 174-186.

Alaee FJ, Benson SDP and Karihaloo BL (2002) A new technique for retrofitting concrete structures. Proceedings of the Institution of Civil Engineers, Structures and Buildings 152(4): 309-318.

Benson SDP and Karihaloo BL (2005a) CARDIFRC ${ }^{\circledR}$ - Development and mechanical properties. Part I: Development and workability. Magazine of Concrete Research 57(6): 347-352.

Benson SDP and Karihaloo BL (2005b) CARDIFRC ${ }^{\mathbb{B}}$ - Development and mechanical properties. Part III: Uniaxial tensile response and other mechanical properties. Magazine of Concrete Research 57(8): 433-443.

Benson SDP, Nicolaides D and Karihaloo BL (2005) CARDIFRC ${ }^{\circledR}-$
Development and mechanical properties. Part II: Fibre distribution. Magazine of Concrete Research 57(7): 421-432.

Bentz DP and Jensen OM (2004) Mitigation strategies for autogenous shrinkage cracking. Cement and Concrete Composites 26(6): 677685.

Brooks JJ, Johari MAM and Mazloom M (2000) Effect of admixtures on the setting times of high-strength concrete. Cement and Concrete Composites 22(4): 293-301.

Cachim PB, Figueiras JA and Pereira PAA (2002) Fatigue behaviour of fiber-reinforced concrete in compression. Cement and Concrete Composites 24(2): 211-217.

Cheyrezy M and Behloul M (2001) Creep and shrinkage of ultra-high performance concrete. In Creep, Shrinkage and Durability Mechanics of Concrete and Other Quasi-brittle Materials: Proceedings of the 6th International Conference (Ulm FJ and Bazant ZP (eds)). Elsevier, London, pp. 527-538.

Farhat FA, Nicolaides D, Kanellopoulos A and Karihaloo BL (2007) CARDIFRC - Performance and application to retrofitting. Engineering Fracture Mechanics 74(1-2): 151-167.

Jensen OM and Hansen PF (1995) A dilatometer for measuring autogenous deformation in hardening Portland cement paste. Materials and Structures 28(7): 406-409.

Jensen OM and Hansen PF (1996) Autogenous deformation and change of the relative humidity in silica fume-modified cement paste. ACI Materials Journal 93(6): 1-5.

Jensen OM and Hansen PF (2001) Autogenous shrinkage and RH change in perspective. Cement and Concrete Research 31(12): 1859-1865.

Jiang Z, Sun Z and Wang P (2005) Autogenous relative humidity and autogenous shrinkage of high-performance cement pastes. Cement and Concrete Research 35(8): 1539-1545.

Karihaloo BL, Alaee FJ and Benson SDP (2002) High-performance fibre-reinforced cementitious composites for retrofitting. International Journal of Materials and Product Technology 17(1-2): 17-31.

Karihaloo BL, Benson SDP and Alaee FJ (2005) CARDIFRC ${ }^{\circledR}$ patent number GB2391010, UK.

Morin V, Tenoudji FC, Feylessoufi A and Richard P (2001) Superplasticizer effects on setting and structuration mechanisms of ultrahigh-performance concrete. Cement and Concrete Research 31(1): 63-71.

Naaman AE and Hammoud H (1998) Fatigue characteristics of high performance fiber-reinforced concrete. Cement and Concrete Composites 20(5): 353-363.

Naaman AE and Harajli MH (1990) Mechanical Properties of High Performance Fiber Concretes: A State-Of-The-Art Report. SHRP National Research Council, Washington DC, USA, Report SHRP-C/ WP-90-004.

Parant E, Rossi P and Boulay C (2007) Fatigue behavior of a multiscale cement composite. Cement and Concrete Research 37(2): 264-269.

Ramakrishnan V, Meyer C, Naaman AE, Zhao G and Fang L (1996) Cyclic behaviour, fatigue strength, endurance limit and models for fatigue behaviour of FRC. Proceedings of the 2nd International RILEM Workshop on High Performance Fiber Reinforced Cement Composites, London. E \& FN Spon, London, pp. 103-116.

Rossi P and Parant E (2008) Damage mechanisms analysis of a multi-scale fibre reinforced cement-based composite subjected to impact and fatigue loading conditions. Cement and Concrete Research 38(3): 413-421.

Yang Y, Sato R and Kawai K (2005) Autogenous shrinkage of highstrength concrete containing silica fume under drying at early ages. Cement and Concrete Research 35(3): 449-456.

Discussion contributions on this paper should reach the editor by 1 March 2011. 